\title{
RESISTÊNCIA E CRIAÇÃO DE UMA GAIA CIÊNCIA EM TEMPOS LÍQUIDOS
}

\section{Resistance and Creation of Gaian Science in "liquid" times}

\author{
Paula Henning ${ }^{1}$
}

Resumo: O presente artigo busca problematizar o campo da ciência a partir do Paradigma Moderno. Provocando o saber científico, pretendo anunciar as marcas do paradigma que constituiu a ciência como a grande e única forma legítima de produzir conhecimento válido. Anunciando um novo tempo contemporâneo, o estudo traz, para discussão, o conceito de Zygmund Bauman sobre Modernidade Líquida. A partir dessas modificações e rachaduras no projeto mais duro de Modernidade, trago o filósofo Friedrich Nietzsche para pensar uma Gaia Ciência, como estratégia de resistência e criação de outras formas de fazer e pensar o campo da ciência na atualidade. Falo de uma ciência do contrassenso, que alia o riso e sabedoria. Um saber alegre que dá as costas à pretensiosa intenção do homem moderno: a obtenção do saber profundo.

Palavras-chave: Ciência. Paradigma moderno. Modernidade líquida. Gaia Ciência.

\begin{abstract}
In this article we seek to problematize the field of sciences with a base in the Modern Paradigm. By provoking scientific knowledge, we intend to announce the marks of the paradigm that has transformed science into the large and sole legitimate form of producing valid knowledge. Announcing new contemporaneous times, the study brings into the discussion the concept of Zygmund Bauman about Liquid Modernity. Based on these modifications and fissures in the Modernity project, we introduce the philosopher Friedrich Nietzsche to think of Gaian Science as a strategy of resistance and the creation of other ways to make and think about the field of sciences nowadays. We talk about nonsense science, which joins laughter and wisdom. A merry knowledge that turns its back to the pretentious intentions of modern man and towards the acquisition of deep knowledge.
\end{abstract}

Keywords: Sciences. Modern paradigm. Liquid modernity. Gaia Sciences.

${ }^{1}$ Universidade Federal do Rio Grande. Rua Hércio Nascimento, 215, Cassino. Rio Grande, RS, Brasil. 96.205-285. paula.henning@ig.com.br 


\section{Introdução}

Fora de sala de aula - "Para lhe mostrar que no fundo o ser humano é um animal de boa índole, eu lembrarei quão crédulo ele foi por tanto tempo. Somente agora, bem tarde e após ingente auto-superação, ele se tornou um animal desconfiado - sim! O ser humano é agora mais malvado do que nunca." - Não compreendo isso: por que deveria o ser humano ser mais desconfiado e malvado agora? - "Por que tem, necessita ter uma ciência” (NIETZSCHE, 2001, p. 80) [grifos do autor].

Provocar o saber científico é o que pretende este artigo. Rachando com o conceito tão caro à modernidade, da ciência como portadora da verdade, legitimadora de conceitos que demonstram o que podemos considerar/aproveitar para nossas vidas, pretendo, nestas poucas páginas, provocar o pensamento do leitor - e o meu também - a respeito da produção do conhecimento científico. Se voltarmos um pouco atrás, veremos que, na virada do século XIX para o XX, a ciência era quase uma nova religião, detentora de verdades, assentada em quase dogmas.

O conhecimento apresentou-se de diferentes formas no processo histórico, querendo o homem compreender o mundo em que vive e a si mesmo. A ciência não foi a única maneira de revelar o conhecimento produzido. Antes dela, e com ela, existiram/existem outras: os mitos, o pensamento mágico, a religião, o senso comum, os saberes populares. Aqui não se elege a ciência o melhor dos óculos para ler o mundo natural, e, muito menos, se defende a exclusividade de um dos artefatos culturais, até porque, por exemplo, mesmo aderindo ao heliocentrismo, usamos o senso comum (ou professamos o geocentrismo) quando nos encantamos com um pôr do sol. Neste texto, estou preocupada em deter minha atenção em um momento histórico que marcou, e ainda marca, nossas vidas, constituindo-nos naquilo que somos: a modernidade. Para isso, trago algumas problematizações desse momento histórico, aproximando o discurso da ciência, antes apresentado como sendo a única forma legítima de ler o mundo.

É importante fazer uma demarcação geográfica: neste texto, minha preocupação versa sobre o mundo ocidental. Os acontecimentos acerca da ciência a que me refiro aqui destinam-se a olhar para a revolução científica que tivemos na virada do século XVI para o XVII, e que vem apresentando sinais de enfraquecimento. Vale referir que esta revolução teve início em 1543, com a publicação do De Revolutionibus de Copérnico, e, em 1687, com a publicação dos Principia, momento fértil de produção de novos conhecimentos e nova visão de mundo. No entanto, a virada epistemológica foi mais decisiva no final do século XVII, com os estudos de Isaac Newton. Além disso, não é possível deixar de comentar que, nas quatro primeiras décadas do século XVII, aparecem os trabalhos seminais de Galileu e de Kepler, de importância decisiva para o processo da revolução científica.

Este estudo, então, tem o propósito não de analisar os conhecimentos produzidos pela sociedade oriental, nem mesmo classificar o que é mais verdadeiro ou melhor para uma sociedade. Ele refere-se a produções de uma sociedade ocidental, marcada pelas produções científicas, e que, apesar de para nós, ocidentais, ser difícil de entender, nem todos os seres humanos viveram/vivem em uma sociedade marcada pela ciência, algumas "nunca desenvol- 
veram o que chamamos ciência" (JUNG, 1996, p. 16). Para a modernidade, quem não consegue separar a natureza da sociedade, o signo da coisa são culturas atrasadas e pouco desenvolvidas. Somente os modernos são capazes de diferenciar a natureza e a cultura, e isso é assim porque somente os modernos possuem o conhecimento científico, aquele que possibilita o projeto de purificação idealizado pela modernidade. Conforme Latour:

Por que o Ocidente pensa assim? Porque justamente ele, e apenas ele, seria algo mais que uma cultura? Nós, ocidentais, não podemos ser apenas mais uma cultura entre outras porque mobilizamos também a natureza. Não mais como fazem as outras sociedades, uma imagem ou representação simbólica da natureza, mas a natureza como ela é, ou ao menos tal como as ciências a conhecem. Se os ocidentais houvessem apenas feito comércio ou conquistado, pilhado e escravizado, não seriam muito diferentes dos outros comerciantes e conquistadores. Mas não, inventaram a ciência, esta atividade em tudo distinta da conquista e do comércio, da política e da moral. (LATOUR, 2000, p. 96)

Inicio, então, trazendo à tona o conceito de paradigma, que será visto ao longo deste estudo. Trato de modernidade como um campo de possibilidades para pensar e fazer ciência no mundo contemporâneo. Para isso, aproximo o conceito de paradigma de Tomas Kunh (2000) ao que chamo de paradigma moderno ${ }^{2}$.

Sendo reconhecidos e compartilhados por uma comunidade, paradigmas são as realizações científicas universalmente reconhecidas que, durante algum tempo, fornecem problemas e soluções modelares para uma comunidade de praticantes de uma ciência (KUHN, 2000, p. 13). Sendo assim, quero, com essa terminologia, anunciar os efeitos discursivos produzidos pelo momento histórico da modernidade que foram se efetivando modos de ser, viver e estar no mundo, constituindo como essa comunidade moderna tornou-se aquilo que foi/é. De acordo com Kuhn (2000), abandonando o paradigma, se abandona a prática de pesquisa que este define. Contudo, o abandono se dá no momento em que tal paradigma não consegue mais explicar os acontecimentos a sua volta, especificamente falando, os acontecimentos científicos. Diante disso, é de se perguntar se os padrões ou modelos aceitos, como chama Kuhn (2000), poderiam se aproximar do conceito de episteme em Foucault (2002), já que se pronuncia através dos discursos que se legitimam como verdadeiros nos espaços e tempos de cada momento histórico? Segundo Foucault (2002), em cada época histórica, existe uma única episteme se pronunciando, através de um conjunto de relações, que imporia, a cada um, as mesmas normas e os mesmos postulados, um estágio geral da razão, uma certa estrutura de pensamento, da qual não saberiam escapar os homens de uma época - grande legislação escrita por mão anônima (FOUCAULT, 2002, p. 217). É então que entendo o conceito de paradigma como

\footnotetext{
${ }^{2}$ Ainda que saiba da elasticidade e da polissemia de conceitos a respeito do termo 'paradigma' - inclusive pelo próprio Thomas Kuhn (2000), em sua clássica obra A estrutura das revoluções científicas - penso ser válida a discussão acerca dessa concepção de mundo moderno. Mais que isso: vale discutir sobre o conceito de paradigma adotando-o em um sentido mais fraco, como evidencio mais adiante neste texto.
} 
uma imagem do que podemos ver e compreender do mundo. É a partir do paradigma vigente que podemos constituir nossas crenças e percepções sobre o mundo, a educação, a ciência. Entretanto, quero aqui fazer uma ressalva do que aproveito dos ensinamentos kuhnianos e do que me coloco à distância deles. Assumo o conceito de paradigma, mas num sentido fraco. Abandonamos a ideia radical de hegemonia paradigmática. Acredito que nos localizamos, sempre, em algum paradigma, constituindo nossa forma de olhar e estar no mundo, constituindo nossas representações desse mundo. Mas acredito, também, que não existem as boas ciências, como anunciou Kuhn (2000), tratando de um paradigma forte nas Ciências Naturais, e que as Ciências Humanas buscavam o estado de maturidade já alcançado pelas Ciências Naturais. Longe dessa hegemonia paradigmática, não atribuo juízo de valor aos paradigmas.

Feitas essas primeiras sinalizações, busco, então, problematizar o paradigma moderno, aquele em que nos situamos e nos produzimos enquanto sujeitos deste espaço contemporâneo. Ao longo de toda modernidade, traçamos a busca pela modernização, pelo progresso do mundo. O rompimento da hegemonia dos saberes e narrativas míticas, das referências teológicas clássicas e todas as metanarrativas transcendentais, fez-nos alcançar uma nova ordem, querendo colocar as verdades consolidadas em questão, para redesenhá-las sob a perspectiva da filosofia e da ciência racionalistas. A ciência moderna buscou/busca dominar e controlar o mundo, como intentavam Bacon, Descartes e os demais propagadores da ciência. Eis, então, a finalidade prática da ciência: explicar a forma da natureza, dominando-a e controlando-a, na busca da compreensão racional da mesma, tornando o homem um ser ativo, ao contrário do paradigma anterior, que colocava o homem como um ser passivo, contemplando a natureza.

Cabe aqui uma análise acerca desse domínio que intenta a ciência moderna: dominar essa ciência pode nos levar a pensar que o contrário também é verdadeiro. Como um cientista que, ao mesmo tempo em que domina, é também dominado pelos saberes que produz. Larrosa (2005), questionando a dureza e os caminhos firmemente delineados do saber legítimo na modernidade, nos coloca a pensar sobre o domínio que exerceu/exerce o saber científico em nossas vidas.

Dominar uma ciência é estar dominado por ela: viver sobre seu abrigo seguro, mas demasiado estreito e já escasso; olhar com suas garras de eficácia comprovada, mas limitadas e sempre imóveis, avançar lenta e pesadamente com seu passo firme e seus métodos carentes de dificuldade, até objetivos modestos e de antemão; mas por caminhos que não permitem sair de seu traçado, nem aspirar a metas incertas e ainda desconhecidas. (LARROSA, 2005, p. 36)

Nesse projeto inicial, chamado por Bauman (2001) de "modernidade sólida", a proposta era derrubar os grandes ideais até então vigentes, querendo instaurar outros grandes ideais em seus lugares: no lugar de Deus, o homem racional, por exemplo. A tentativa do Projeto Oficial da Modernidade era "descobrir ou inventar sólidos de solidez 'duradoura', solidez em que se pudesse confiar e que tornaria o mundo possível e, portanto, administrável" (BAUMAN, 2001, p. 10, grifo do autor). Assim, o exercício da dúvida e do questionamento era desejável na direção exclusiva da derrubada de algumas verdades para consolidação de outras, ainda mais perfeitas e acabadas. 
A falência dessa explicação total, da constituição moderna, do projeto de purificação faz com que coloquemos sob suspeita a modernidade. Compreender que o projeto inicial da modernidade já não dá mais conta das perplexidades contemporâneas faz com que muitos de nós questionemos as verdades cristalizadas por séculos. Diante disso, Bauman (2001) nos traz uma metáfora muito ilustrativa a respeito de um novo tempo: se antes chamávamos de "modernidade sólida" esse projeto mais duro e oficial de modernidade, é em tempos de fluidez e borramento de fronteiras que o polonês nos sugere tratar desse tempo contemporâneo como uma "modernidade líquida".

Mudanças nesse projeto inicial da modernidade levaram-nos na direção de outro tipo ou consistência de modernidade, uma nova fase na história da modernidade, inaugurada, especialmente, pelas mudanças no capitalismo industrial, que, assumindo novas configurações, nos leva a outros modos de organização social. A gana pela novidade, pela mudança, pela transformação, em grande parte decorrente dos avanços de natureza tecnológica de uma sociedade dita pós-industrial, está presente em nosso tempo. No entanto, a mudança parece ter se tornado não apenas a tentativa de trocar novamente de ideais, mas implica uma espécie de compulsão à mudança, onde o que vale é a permanente liquidez dos ideais que estão sempre em vias de desfazer-se. Por isso, para ele, estamos num estado de fluidez.

Os fluidos se movem facilmente. Eles "fluem", "escorregam", "respingam", "transbordam", "vazam", "inundam", "borrifam", "pingam"; são "filtrados", "destilados"; diferentemente dos sólidos, não são facilmente contidos. (BAUMAN, 2001, p. 8, grifos do autor)

As transformações sociais, culturais, econômicas, políticas apresentadas por nossa sociedade refletem a mudança de uma nova ordem, através da flexibilização como principal característica desse novo tempo. Um tempo em que as transformações acontecem sem pedir licença, em que se exige a flexibilização na nossa forma de ser, viver e estar no mundo como pessoa e como profissional.

Assim, se num determinado momento - ainda não superado completamente - buscávamos incessantemente um padrão estabelecido com margens rígidas, hoje, o padrão que buscamos é aparentemente fluido, que nunca cessa de mudar e exigir permanentemente novas configurações. De qualquer forma, ainda existem margens, por vezes mais rígidas, por vezes mais fluidas, mas que, de um jeito ou de outro, delimitam nossas formas de ser, estar e agir neste mundo. Isso não garante, como se pôde pensar romanticamente num determinado momento, que o elogio da mudança seja a garantia de efetiva transformação para melhor ou de maior liberdade na criação de nossos modos de existir. O que experimentamos é uma aceleração das mudanças formais que nem sempre altera o caráter mais original da própria modernidade. Como sugere Bauman:

A sociedade que entra no século XXI não é menos "moderna" que a que entrou no século XX; o máximo que se pode dizer que ela é moderna de um modo diferente. O que a faz tão moderna como era mais ou menos há um século é o que distingue a modernidade de todas as outras formas históricas do convívio humano: a compulsiva e obsessi- 
va, contínua, irrefreável e sempre incompleta modernização; a opressiva, e inerradicável, insaciável sede de destruição criativa (ou a criatividade destrutiva, se for o caso: de "limpar o lugar" em nome de um "novo e aperfeiçoado" projeto: de "desmantelar", "cortar", "defasar", "reunir" ou "reduzir", tudo isso em nome da maior capacidade de fazer o mesmo no futuro - em nome da produtividade ou da competitividade). (BAUMAN, 2001, p. 36, grifos do autor)

Após essas problematizações de Bauman (2001) e outros tantos autores a respeito de nosso momento atual, penso ser imprescindível debruçarmos nosso olhar sobre as modificações presentes no campo científico. Trata-se não somente daquela configuração mais dura ou típica da modernidade inicial, industrial, política e eticamente determinada pelas mudanças do século XVII, mas, também, de formas contemporâneas de modernidade, onde a busca pela flexibilização e fluidez das formas não garantiu a inauguração de uma nova episteme.

Assim, não busco, nessa Modernidade Líquida, a solução para as mazelas sociais. Compartilho com Latour (2000) o entendimento de que ela é um sintoma. Um sintoma de uma sociedade que vive as metanarrativas modernas, mas, paradoxalmente, dá às costas na tentativa de entender como esses discursos vêm se produzindo, fazendo nos tornar aquilo que somos. Um sintoma que deixa para trás o desvelamento das coisas, a essência do sujeito autocentrado, a verdade verdadeira das coisas, a ciência como única e legítima explicação do mundo. Ao mesmo tempo, esse sintoma é pouco conhecido por nós. Sabemos quais metanarrativas questionar, mas quais caminhos trilhar a partir daí? "Um outro terreno, muito mais vasto, muito menos polêmico, encontra-se aberto para nós, o terreno dos mundos não modernos. É o Império do Centro, tão vasto quanto a China, tão desconhecido quanto ela" (LATOUR, 2000, p. 52).

Pensar em que tempo estamos parece-me ser um questionamento que, ainda hoje, muitos de nós nos fazemos: um tempo de rupturas epistemológicas, metodológicas, educacionais, sociais, políticas, econômicas; um tempo em que anunciamos novas maneiras de olhar o mundo, olhar a ciência, de pensar: o que hoje conta como verdade neste espaço-tempo, neste contexto cultural? Indagar sobre isso é, pelo menos, abrir possibilidades e novos caminhos de aceitar outras formas de ver o mundo.

Entretanto, muitos de nós, homens e mulheres desse movimento contemporâneo, não estamos acostumados a viver em um mundo sem certeza e sem segurança, sem a claridade dada pelas verdades científicas. Isso resulta do fato de termos sido produzidos pelo paradigma moderno. Nietzsche (2001) nos inquieta ao colocar a vida, não como um argumento fincado na razão, mas como algo que pode ser revisto, reelaborado, produzido com um outro olhar para o mundo, não mais (apenas) com os óculos da ciência moderna.

Ajustamos para nós um mundo em que podemos viver - supondo corpos, linhas, superfícies, causas e efeitos, movimento e repouso, forma e conteúdo: sem esses artigos de fé, ninguém suportaria hoje viver! Mas isto não significa que eles estejam provados. A vida não é argumento; entre as condições para a vida poderia estar o erro. (NIETZSCHE, 2001, p. 145) 
Quebrando as ideias iluministas, colocando sob suspeita a ideia de verdade, demarcando-a como historicamente produzida, o filósofo vem na contramão de todo um pensamento instituído como verdadeiro no século XIX. Aliás, ele mesmo, em seus escritos, nos relata dizendo estar fora do seu tempo, pois alguns nascem postumamente (NIETZSCHE, 2003). Dentre esses, está Nietzsche que, em seu tempo, pouco foi lido e discutido. Entretanto, hoje, é um autor que traz, em seus escritos, marcas desse tempo que até parece ainda por chegar, desse momento ambíguo e paradoxal em que nos situamos, na contemporaneidade.

Assim, essa nova configuração de modernidade não se caracteriza como um momento histórico, posterior à modernidade. Nietzsche (2001; 2003 e 2004) nos dá pistas, desde o século XIX, de um outro olhar para além do mundo científico, trazendo, em seus escritos, críticas ao modelo linear da ciência, o que me leva a dizer que é um precursor da pós-modernidade. Foucault (2005, p. 33) situa Nietzsche como um homem do século XIX, que antecipou genialmente a época que vivemos hoje.

Relegando a ideia linear de um tempo após a Modernidade, percebemos, nos tempos contemporâneos, um movimento paradoxal, em que olhamos para o passado e nos entendemos constitutivos dele, mas damos as costas a muitas metanarrativas corporificadas no tempo moderno, dentre essas metanarrativas, situamos a ciência como única maneira possível de ler o mundo.

Com novas configurações nesse cenário contemporâneo e problematizações da universalidade e supremacia da ciência, enfraquecemos, é certo, todos os ideais modernos. Com isso não digo que a ciência deixa de existir, ela toma, agora, um local não privilegiado, ela é, dentre tantos outros saberes, uma das muitas formas de lermos o mundo (CHASSOT, 2003).

Ao ementar a Constituição [da Ciência], continuamos acreditando nas ciências, mas ao invés de encará-las através de sua objetividade, sua frieza, sua exteriorialidade - qualidades que só tiveram um dia devido ao tratamento arbitrário da epistemologia -, iremos olhá-la através daquilo que elas sempre tiveram de mais interessante: sua astúcia, sua experimentação, sua incerteza, seu calor, sua estranha mistura de híbridos, sua capacidade louca de recompor os laços sociais. (LATOUR, 2000, p. 140)

Pensando, enfim, nessa outra concepção de ciência, a solidificação moderna se dilui. Abrem-se outros horizontes e olhares para o caminho científico. A prática científica, não mais obrigada a prescrever o mundo, agora, pode, talvez, abandonar um pensamento totalizante de explicação do mundo, por meio da razão moderna. Mudam-se as análises, as metodologias, os problemas, as promessas... O mundo da razão soberana científica morreu, abrindo espaços para uma ciência alegre (NIETZSCHE, 2001). Um saber que, longe de querer representar o que é mesmo essa realidade, percebe-se frágil e limitado diante das questões do conhecimento e do mundo. Essa perspectiva pós-moderna de ciência despede-se das metanarrativas do Iluminismo - ainda que saibamos que o projeto iluminista nunca morreu, mas também nunca se concretizou na sua totalidade... -, do sujeito transcendental, da razão onipotente, da verdade objetiva e das essencializações e universalizações do conhecimento.

Muitos de nós podemos nos sentir frustrados de estarmos num momento em que a binaridade e a certeza cedem espaço à multiplicidade e à insegurança. Nesse sentido, Foucault 
(2005) nos põe a pensar sobre esse novo tempo que nos coloca múltiplas formas de olhar o mundo e a vida.

Compreende-se que alguns lamentem sobre o vazio atual e desejem, no âmbito das idéias, um pouco de monarquia. Mas aqueles que, uma vez em suas vidas, encontraram um tom novo, uma nova maneira de olhar, uma outra maneira de fazer, estes, acredito, jamais experimentarão a necessidade de se lamentarem de que o mundo é um erro, a história, saturada de inexistências, e já é hora de os outros se calarem para que, se possa ouvir a sineta de sua reprovação... (FOUCAULT, 2005, p. 306)

Reprovar a seriedade da ciência, a insatisfação do incerto, a continuidade do progresso e da ordem na sociedade. A classificação e categorização do que conta como verdade demarca não somente a modernidade, mas o tempo anterior ao nascimento da ciência. Ambos os paradigmas são constituídos através de ídolos: de um lado, está Deus, um ser superior, nos trazendo a ideia de transcendência; do outro, está a ciência, marcando o conhecimento legítimo. Nietzsche (2004), então, questiona a ideia de que não houve uma ruptura epistemológica entre esses dois paradigmas, já que houve apenas uma substituição de ídolos.

Comparo a monarquia, de que trata Foucault (2005) na citação acima, à troca de ídolos de que fala Nietzsche (2001). Estamos acostumados a sermos guiados por alguém ou alguma coisa: seja a religião ou filosofia, seja a própria ciência. Rorty nos alerta: "não há nada de errado na ciência, só há algo de errado com a tentativa de divinizá-la" (2002, p. 51). E quando a divindade da ciência é colocada em xeque? O que fazer? Quem seguir? Esse novo tempo contemporâneo, de problematização (e por que não dizer, também, de provocação?) não abre lugar a um outro ídolo ou monarquia. Não pretende nada além do que dar adeus às metanarrativas (SILVA, 1996), a essas grandes verdades. Quer, então, colocar sob suspeita as verdades absolutas, o único caminho a ser seguido (a ciência), as regras para ser considerado um saber legítimo. Suspeita, então, da metalinguagem, daquela linguagem capaz de dizer tudo sobre as coisas. Pergunta-se sobre o que dizem sobre as coisas e não o que as coisas são. Põe-se a pensar sobre as coisas, põe-se a pensar sobre a ciência. Veiga-Neto (1998) nos remete a refletir sobre esse novo tempo, que é chamado, por ele, de pós-moderno:

Assim, o que se coloca para o pós-moderno não é propriamente refutar o moderno; o que ele quer é apenas trabalhar sem recorrer à transcendência da razão e do sujeito, à dialética e assim por diante. Esse apenas é tudo, pois o que o pós-moderno subtrai do pensamento moderno são seus próprios fundamentos, na medida em que esses fundamentos vinham sendo aceitos como incondicionais, supra-históricos, últimos, transcendentais. (VEIGA-NETO, 1998, p. 146)

Os fundamentos do pensamento moderno de que trata Veiga-Neto (1998), ao ser balizado/indagado, leva-nos a uma crise, a um momento de incertezas e inseguranças. Digo isso pensando no espaço-tempo em que vivemos, pensando em nós como humanos constituídos a partir dos pressupostos colocados pela modernidade. Pensar que verdades até, então, sempre aceitas podem ser refutadas, que podem existir outras formas de olhar o mundo além dos óculos científicos, são questões que, pelo menos a mim, incomodam. Incomodar não no sentido negativo, mas no sentido de mexer com nossos saberes tão bem fincados em um 
paradigma que busca verdades e, com elas, nos dá segurança e tranquilidade. O desmanchamento da modernidade, pelo menos em seu sustentáculo das verdades verdadeiramente verdadeiras, parece eclodir em nossos tempos contemporâneos. Criar condições para analisar esses movimentos atuais em um tempo ambíguo e paradoxal, que se instala, sem pedir licença, em nossa vida pública e privada; pensar esse novo tempo e compreender que alguns dos sólidos alicerces modernos vêm se rachando, produzindo fissuras e dobras, tornam-se desafios contemporâneos, estejamos nós preparados ou não.

Assim, essa virada em nossas mais caras certezas é um tempo paradoxal, já que convivemos com dois ethos. Ela acontece trazendo consigo uma crise, pois questiona as estruturas que, até então, eram os sustentáculos de toda nossa maneira de olhar para as coisas. Na medida em que colocamos sob suspeita nossos valores, ideais, utopias estamos produzindo, em nós mesmos, uma ruptura epistêmica. A crise a que me refiro está relacionada não com a troca de um paradigma por outro, mas a um olhar avesso a toda produção moderna que nos constituiu/constitui/constituirá.

De uma época marcada pela densidade em questões científicas, esse movimento apresenta-se como um tempo instantâneo, situado em um espaço "leve, etéreo, transparente ou então num espaço obscuro, pedregoso, embaraçado" (FOUCAULT, 2001, p. 413).

Sendo então um espaço heterogêneo, inusitado, complexo, ambíguo para nós, não se torna fácil viver em um tempo como esse. Como viver neste mundo? Quais propósitos devemos (ou não) ter neste novo espaço-tempo? Que pensares e fazeres neste movimento de leveza, de incertezas e formas que cada um de nós lhe atribui? Pensar em que tempo estamos e em que tempo vivemos parecem-me ser questionamentos necessários para refletirmos sobre a ciência que, até pouco tempo atrás, era vista como linear, clara e precisa.

Esse olhar, essas mudanças e esse momento paradoxal inquietam-nos para pensarmos sobre os conhecimentos científicos agora vistos como provisórios, incertos, instáveis. A ciência é uma das muitas maneiras de produzirmos conhecimentos. Não vista mais como a melhor / a única condição de chegarmos à verdade ${ }^{3}$, ela se desmancha, se constitui como um saber importante e necessário tanto quanto o senso comum, a literatura e as artes. Assim, percebemos que a indispensável busca por querermos constituir tudo em ciência fragiliza-se. Afinal, se destruirmos a hierarquização de saberes, que, desde a Idade Clássica, acompanhanos com a Filosofia e a Teologia, não se faz mais necessário lutar pela legitimidade científica, já que ela perde o caráter de única produção de conhecimento válido.

Dessa forma, a linearidade e a repetição de respostas aos problemas muito próximos demonstram-se, nos dias atuais, vulneráveis à complexidade do momento vivido por nós. Assim, parece ocuparmos uma posição humilde e modesta. Não mais responsável por fornecer respostas a todas as problemáticas apresentadas, a própria ciência se entende mais limitada aos processos epistemológicos que constituem o mundo hoje. Lyotard (1993) bem retrata esse movimento irreversível vivido pela complexidade de um mundo em transição.

\footnotetext{
${ }^{3}$ É importante ressaltar que a intenção de se chegar na verdade perde sua razão de ser, já que, para esse novo tempo, ela não existe. O que existe, parafraseando Nietzsche (2001), é uma vontade de verdade.
} 
O que se esboça, assim, como horizonte para o teu século é o crescimento da complexidade na maior parte dos domínios, incluindo os modos de vida, a vida quotidiana. E assim se circunscreve uma tarefa decisiva: tornar a humanidade apta a adaptar-se a meios de sentir, de compreender e de fazer muito complexos, que se excedem o que a humanidade procura. Essa tarefa implica no mínimo a resistência ao simplismo, as palavras de ordem simplificadoras, aos pedidos de clareza e facilidade, aos desejos de restaurar valores seguros. (LYOTARD, 1993, p. 103)

Nesse sentido, compreendo a necessidade de colocarmos em suspenso as metanarrativas, os grandes relatos que aprendemos a aceitar, corporificando nossa cultura, nossos pensares e nosso fazeres. Essa ruptura não é tranquila para nenhum de nós, é, antes de mais nada, uma condição que se coloca presente em nossas vidas, constituindo transformações, colocando-nos em ambiguidade diante dos saberes ditos verdadeiros.

Assim, esse horizonte de que trata Lyotard (1993) configura a constituição de um tempo paradoxal, marcado pelos diálogos entre modernidade e pós-modernidade, entendendo a verdade como produção nossa, como interpretação, e não como algo dado, acabado, pronto para ser descoberto por quem seja capaz de fazê-lo.

Com tudo isso, não se tem a pretensão de dar um fim à modernidade, mas questionar a todos nós das verdades consagradas por séculos. Ao contrário do que fez a modernidade, colocando-se exclusivamente como a única forma possível de se chegar aos conhecimentos, através da ciência, substituindo ídolos, esse novo tempo assume um caráter mais modesto: o que conta como verdade hoje? Quais as condições para validação da verdade?

Diante disso, compreender que constituímos as coisas das quais falamos é um golpe na base epistemológica da modernidade. Entendemos a ciência como produtora de um discurso que institui e legitima saberes, não por ser mais verdadeiros, mas por ser um campo que se constitui através de um consistente regime de verdade que tomou forma no século XVI, pela rigorosidade, matematização e linearidade bem-vindas ao momento histórico, social, político, econômico e cultural da época moderna.

As condições da pós-modernidade apresentam-se, então, através de mudanças microfísicas no olhar sobre as coisas, inquietações acerca da redenção, prometeísmo, práticas progressistas marcadas pelos ideários de educação. Colocam-nos em uma condição de humildade, de vigilância epistemológica, em que a intelectualidade do modernismo se assume limitada e perplexa diante de suas tarefas mais singelas. Dentre elas, encontramos a tarefa de transmitir verdades produzidas e constituídas por esse espaço-tempo cultural. Como nos diz Corazza (2002, p. 31):

[...] ser capaz de pensar o impensável, o intratável, o impossível, o nãopensado do pensamento educacional. Embaralhar a sintaxe e organizar o pensamento numa lógica às avessas, constituindo-se como um pensamento-outro da Educação. Pensamento que ignora as verdades recebidas, metamorfoseia o valor das opiniões estabelecidas, busca sus- 
pender e transvalorar o valor de todos os valores herdados. Liberta-se do culto à totalidade, transcendência, dialética, metafísica, humanismo, bem como dos casais de tensões certo/errado, culpa/castigo, bem/ mal, morte/vida. Foge do pensamento único para tornar as singularidades possíveis, afirmar o múltiplo, multiplicar os devires.

Frente a esse cenário de mutação apresenta-se um novo tempo e um novo olhar sobre a ciência. Nesse sentido, resta-nos questionar a ordem discursiva imposta: afinal, para que serve a ciência? Que outras formas possíveis de pensar o mundo, a Educação, o currículo, que não através dos óculos da ciência? Que visão de ciência temos hoje? Qual ciência vem sendo exercida por nós professores? O que podemos problematizar para assumir um discurso (talvez não o que está na ordem, mas na desordem das coisas) que olhe ao avesso para a legitimidade da ciência?

Questões como estas parecem estar na pauta de discussão quando pensamos no nosso trabalho enquanto professores que formam novos educadores, e, assim, pensamos também nas implicações disso para o campo da educação científica. Nesse sentido, ao tratar de pós-modernidade e ciência gostaria de cutucar - minimamente - cada professor para que pensemos em nossas ações docentes. Como bem trata Lopes e Jafelice (2009), a ciência se apresenta hoje como um saber acima do bem e do mal, uma saber com um prestígio social que parece não dar conta do local inabalável em que se instalou... Para que essa discussão sobre o campo da ciência possa ser trazida à tona, sugiro pensarmos no tempo em que vivemos, no mundo contemporâneo e nas mudanças cotidianas que entram em nossas vidas de uma forma cada vez mais líquida e escorregadia. Sendo assim, sugiro pensarmos na pós-modernidade e nos atravessamentos que, queiramos ou não, vêm abalando as certezas tão sólidas trazidas pela ciência.

Assim, ainda hoje, por anacrônico que seja, a ciência continua sendo mostrada como um empreendimento humano objetivo, que detém a verdade sobre a realidade - ontologicamente falando - e é praticamente isenta de forças políticas e ideológicas - basta conversar com estudantes, professores, alunos etc. O contraditório e preocupante é que este tipo de atitude é adotado inclusive por quem se considera educador científico! Ou seja, ignorantes ou omissos quanto a tal discussão, os professores de ciências contribuem muito para reforçar a imagem distorcida de ciência que tem sido fomentada pelos meios de comunicação, cientistas, livros didáticos e cursos de licenciatura em geral. Isso tudo contribui para a idéia de que a ciência moderna ocidental é a única forma de conhecimento válida, ou a melhor forma criada pela humanidade. (LOPES; JEFELICE, 2009, p. 9)

Nessas condições, a preocupação de que muitos educadores mantêm-se longe de questões científicas (JAFELICE, 2008) não parece absurda. Muito pelo contrário! Torna-se uma preocupação necessária a nós professores do século XXI. Trazer questões alicerçadas não somente ao campo da ciência em si, mas vinculadas a discussões do campo da filosofia da 
ciência, dos aspectos políticos, sociais, econômicos e culturais da ciência é um desafio que este novo tempo nos apresenta ${ }^{4}$.

Para nos colocarmos no exercício do pensamento, trago um autor que problematizou essa forma de olhar para a ciência e, por isso mesmo, ficou conhecido como um dos inimigos da ciência: Paul Feyerabend (1989). Colocando em xeque a linearidade e a exatidão do método científico proposto por Bacon e propagado pela modernidade, pondo sob suspeita os ferrolhos da ciência moderna, Feyerabend (1989) trouxe, para as discussões científicas, um verdadeiro anarquismo epistemológico. Nas palavras do autor, em sua obra Contra o método, que pode ser considerada como fundante do anarquismo epistemológico:

[...] dada uma regra qualquer, por "fundamental" e "necessária" que se afigure para a Ciência, sempre haverá circunstância em que se torna conveniente ignorá-la, como adotar regra oposta. [...] Qualquer idéia, embora antiga e absurda, é capaz de aperfeiçoar nosso conhecimento. [...] o conhecimento de hoje pode, amanhã, passar a ser visto como conto de fadas; essa é a via pelo qual o mito mais ridículo pode vir a transformar-se na mais sólida peça da Ciência. (FEYERABEND, 1989, p. 71, grifos do autor - assinalar os grifos)

As considerações de Feyerabend (1989) se apresentam como inquietações diante do pensar a solidificação de uma ciência mimética, especulativa que, com seu único método, impôs a verdade verdadeira das coisas, do mundo. Seu anarquismo epistemológico perturba o racionalismo, as doutrinas, a moral, a verdade. $\mathrm{O}$ autor nos põe a pensar que talvez a verdade, tão idealizada pela ciência moderna, não seja tão importante assim... Um golpe num foco central para a ciência mimética, especulativa e linear parece ter conduzido o trabalho do físico austríaco que foi na contramão da produção das ciências naturais - ciências de onde ele mesmo advinha -, colocando sob suspeita a estrutura e o método científico até então em voga.

Padrões universais e tradições rígidas são identificados por Feyerabend (1989) como promotores do atraso da ciência. O único princípio em que ele se fundamenta é o tudo vale. Ou seja, abandonando a segurança e as certezas dogmáticas a que pretende chegar a ciência, o anarquismo epistemológico intenta a subversão a qualquer tipo de produção que procure construir alicerces maciços e necessários para se chegar ao verdadeiro conhecimento. Paulo Terra (2000), ao apresentar algumas idrias do anarquismo epistemológico, nos põe a pensar sobre o argumento de que tudo vale. Ora, "tudo vale no sentido de não limitar o pensamento da ciência a um único método, tudo vale quando se trata de promover a riqueza de idéias" (TERRA, 2000, p. 48).

Perante isso, entende o autor que a ciência é uma das muitas formas de produzirmos conhecimento válido, e, nesse sentido, parece necessário considerarmos essa outra consigna para nossa educação científica. Os saberes resultantes do conhecimento científico se fazem necessários assim como os mitos, as religiões, a filosofia. Nas palavras de Feyerabend (1989, p. 279):

${ }^{4}$ A este respeito sugiro a leitura do artigo de Jafelice (2008). 
[...] A ciência não é sacrossanta. As restrições que impõe (e são essas restrições, embora não seja fácil relacioná-las) não são necessárias para que venhamos a alcançar gerais, coerentes e frutíferas concepções do mundo. Há mitos, há dogmas de teologia, há metafísica e há muitas outras maneiras de elaborar uma cosmovisão. [...] E, assim, o anarquismo não é apenas possível, porém necessário tanto para o progresso interno da ciência, quanto para o desenvolvimento de nossa cultura como um todo. E a razão, por fim, reúne-se a todos aqueles outros monstros abstratos, como Obrigação, Dever, Moralidade, Verdade e seus antecessores mais concretos, os Deuses, que já foram usados para intimidar o homem e restringir-lhe o livre e feliz desenvolvimento - e se vai desvanecendo...

O que se percebe do anarquismo epistemológico de Feyerabend (1989) são suas rupturas e desmanchamentos de alguns preceitos da ciência moderna a partir do método científico. Frente a isso, talvez valesse pensarmos nos ensinamentos feyerabendianos para produzirmos uma educação científica mais frouxa, móvel e, como queria o próprio autor, fazendo da ciência algo mais alegre, mais feliz, nos possibilitando sorrir. Algumas considerações do anarquista me remetem a determinados posicionamentos que, hoje, consideramos importantes para pensarmos de outra forma o saber cientifico. Nietzsche (2001) é um autor que nos leva a pensar sobre a ciência como um saber alegre - não é sem razão que um de seus livros mais importantes se chame $A$ gaia ciência. Quantas vezes nosso saber científico se prende nas amarras lineares e estanques de quantificação de artigos, publicações, produções, e nos vemos atolados num mar de trabalho que, muitas vezes, é somente feito para cumprir a ordem do dia? Quem sabe devêssemos pensar nessa ciência como um saber alegre, através da felicidade de que fala Feyerabend (1989) e Nietzsche (2001), e fazer uma ciência do contrassenso?

Esse olhar ao avesso, para a ciência e tantos outros discursos marcados como legitimadores de nossa época, é o que intenta esse movimento contemporâneo. Quando colocamos em xeque as verdades consagradas e indiscutíveis do paradigma científico, tais concepções tornam-se problemas que perturbam nosso cotidiano. Rejeitando a totalização de um saber, colocamos sob suspeita a verdade verdadeira da ciência. Assim, a discussão não está em se a ciência deve ou não existir, mas em entendermos como ela produz efeitos regulamentados de poder e verdade. Vale colocarmos em discussão essas questões quando se trata de pensar a educação científica no cenário contemporâneo.

Ainda hoje, a categorização de saberes produzidos pela ciência tem suas marcas, indicando como se dá o conhecimento mais sólido, o mais certo, o mais verdadeiro. Conhecemos inúmeras classificações para as Ciências Naturais e Humanas: para as primeiras, ciências duras (ciências hard); para as segundas, ciências moles (ciências soft). Vale evidenciar quanto essa classificação hierarquiza e padroniza valores e ideais acerca do fazer ciência. Podemos considerar que essa denominação, com sua evidente discriminação - com a qual nos deparamos com frequência, em particular, em cientistas das Ciências Naturais -, demarca, para todas as demais ciências que não conseguem assumir a observação, a experiência, a exatidão, a quantificação e a neutralidade, um estatuto de menos científicas do que a ciência mãe, aquela geradora, a partir de uma matriz definidora de cientificidade. Enfim, entende-se assim que a produ- 
ção de um discurso acerca da sustentação e da durez̧a das Ciências Naturais é, então, uma verdade desse mundo.

Essas e muitas outras verdades produzidas e instituídas no mundo contemporâneo mobilizam-nos a investigar: por que há um saber que é legitimado como científico, e outro que não carrega consigo este discurso? Quais condições de possibilidade existem para que se faça esta distinção?

Neste sentido, o presente texto intenta instigar o exercício do pensar, o questionamento de conceitos, de padrões e de valores estabelecidos. Olhar a ciência não como algo binário, como olhamos ao longo de todos esses séculos - boa ou ruim -, mas identificá-la como um construto humano, demasiado humano...

[...] Ainda hoje vocês têm a escolha: ou o minimo de despražer possivel, isto é, a ausência de dor [...] ou o máximo de despražer possivel, como preço pelo incremento de uma abundância de sutis prazeres e alegrias, até hoje raramente degustados! Caso se decidam pelo primeiro, caso queiram diminuir e abater a suscetibilidade humana à dor, então têm de abater e diminuir também a capacidade para alegria. Com a ciência pode-se realmente promover tanto um quanto outro objetivo! Talvez ela seja agora mais conhecida por seu poder de tirar ao homem suas alegrias e torná-lo mais frio, mais estatuesco, mais estóico. Mas ela poderia se revelar ainda como a grande causadora de dor! - E então talvez se revelasse igualmente o seu poder contrário, sua tremenda capacidade para fazer brilhar novas galáxias de alegria! (NIETZSCHE, 2001, p. 63, grifos do autor)

Diante desse entendimento, a ciência não demarca uma dualidade: a dor e a alegria são seus objetivos. Não como contraditórios, mas como produções humanas que fazem da ciência muito mais do que produzir conhecimentos universais e atemporais, mas como um saber que nos traz a alegria, o sentimento de flutuar, de errar, de sermos tolos por vezes; e, como queria Nietzsche (2001), que se faça, da ciência, uma ciência alegre, uma ciência do contrassenso, uma ciência que alia o riso e a sabedoria. Um saber alegre que dá as costas à pretensiosa intenção do homem moderno: a obtenção do saber profundo.

No entanto, sabemos a dificuldade de se viver num mundo como esse, num mundo em que, ao mesmo tempo que nos forçamos a problematizar a ciência, encontramos uma ordem discursiva instaurada: a ciência como o grande regime de verdade da modernidade. Parece que exercermos sobre nós mesmos outra forma de viver, lutarmos para romper com estratégias de governo da conduta que muitos discursos exercem sobre nós, seria uma possibilidade de resistência e criação de outros olhares para o campo da ciência. A questão não é "derrotar" a ciência, mas criar fendas para que possamos olhá-la de uma outra forma e, sendo assim, compormos novas formas de produzi-la, aceitando o desafio nietzschiano de dançarmos à beira do abismo... Se esses discursos que circulam precisam que os aceitemos e os incorporemos como nossos, temos a possibilidade de rompermos com eles e traçarmos, talvez, aquilo que Nietzsche (2003) nos anunciou ser sua vida: um ensaiar e perguntar. Essa talvez seja a possibilidade para nos indagarmos acerca daquilo que nos tornamos e ensaiarmos 
outras possibilidades de vida; e, para nós que trabalhamos com a ciência, outras possibilidades de traçarmos e compormos a ciência na atualidade. Talvez, seja possível uma outra ciência, uma Gaia Ciência.

\author{
Dança agora sobre mil dorsos, \\ Dorsos de ondas, malícias de ondas - \\ Salve quem novas danças cria! \\ Livre - seja chamada a nossa arte \\ E gaia - a nossa ciência! (NIETZSCHE, 2001, p. 313)
}

E é com este tom que encerro esta escrita: que ela sirva - a mim ela serviu! - como rachaduras para se pensarem os espaços da ciência em que nos situamos (escolas, universidades, laboratórios científicos), que ela sirva como flechas que se cruzam ininterruptamente na nossa identidade de cientistas; que sirva, enfim, para fazermos dançar a ciência, para fazermos bailar nossos espaços profissionais como cientistas da educação, e, para isso, que criemos nossos próprios passos de dança ao longo do caminho, ensaiando e perguntando, pois, como sugere Nietzsche (2002), o caminho não existe.

\title{
Referências
}

BAUMAN, Z. Modernidade líquida. Rio de Janeiro: Jorge Zahar, 2001.

CHASSOT, A. Educação consCiência. Santa Cruz do Sul: EdUNISC, 2003.

CORAZZA, S. Para uma filosofia do inferno na educação: Nietzsche, Deleuze e outros malditos afins. Belo Horizonte: Autêntica, 2002.

FEYERABEND, P. Contra o método. 3. ed. Rio de Janeiro: Francisco Alves, 1989.

FOUCAULT, M. Ditos e escritos II: arqueologia das ciências e história dos sistemas de pensamento. Rio de Janeiro: Forense Universitária, 2005.

Ditos e escritos III: estética - literatura e pintura, música e cinema. Rio de Janeiro: Forense Universitária, 2001.

A arqueologia do saber. 6. ed. Rio de Janeiro: Forense Universitária, 2002.

A ordem do discurso. 10. ed. São Paulo: Loyola, 2004.

JAFELICE, L. C. Educação científica, pós-modernidade e transdisciplinaridade. In:

MARTINS, R. A. et al. (Ed.). Filosofia e história da ciência no cone sul. Campinas: Associação de Filosofia e História da Ciência do Cone Sul (AFHIC), 2008. p. 285-293.

JUNG, C.G. Prefácio. In.: WILHELM, Richard. I Ching o livro das mutações. $17^{a}$ ed. São Paulo: Editora Pensamento, 1996.

KUHN, T. A estrutura das revoluções científicas. São Paulo: Editora Perspectiva, 2000. 
Henning, P.

LATOUR, B. Jamais fomos modernos: ensaios de antropologia simétrica. Rio de Janeiro, Editora 34, 2000.

LARROSA, J. Nietzsche e a educação. Belo Horizonte: Autêntica, 2005.

LYOTARD, J.-F. O pós-moderno explicado às crianças. Lisboa: Dom Quixote, 1993.

LOPES, F. A. D.; JAFELICE, L. C. Educação científica no contexto pós-ontológico: um novo ensino de ciências para uma nova imagem da ciência. In: SIMPÓSIO NACIONAL DE ENSINO DE FÍSICA, 18., 2009, Vitória. Anais... São Paulo: Sociedade Brasileira de Física, 2009. Disponível em: <http://www.sbf1.sbfisica.org.br/eventos/snef/xviii/sys/ resumos/T0420-1.pdf>. Acesso em: 26 out. 2011.

NIETZSCHE, F. A gaia ciência. São Paulo: Companhia das Letras, 2001. 2003.

Ecce homo: de como a gente se torna o que a gente é. Porto Alegre, L\&PM,

_ Aurora: reflexões sobre os preconceitos morais. São Paulo: Companhia das Letras, 2004.

PETERS, M. Pós-estruturalismo e filosofia da diferença. Belo Horizonte: Autêntica, 2000.

RORTY, R. Objetivismo, relativismo e verdade: escritos filosóficos I. Rio de Janeiro: Relume Dumará, 2002.

SILVA, T. T. da. O adeus às metanarrativas educacionais. In: --Identidades terminais. Rio de janeiro: Vozes, 1996. p. 236-250.

TERRA, P. Pequeno manual do anarquista epistemológico. Ilhéus: Editus, 2000.

VEIGA-NETO, A. Ciência e pós-modernidade. Revista Episteme, Porto Alegre, v. 3, n. 5, p. 143-156, 1998.

Paradigmas? Cuidado com eles! In.: COSTA, M. V. (Org). Caminhos

investigativos II: outros modos de pensar e fazer pesquisa em educação. Rio de Janeiro: DP\&A, 2002. p. 35-48.

Artigo recebido em 28/06/2011. Aceito em 21/01/2012. 